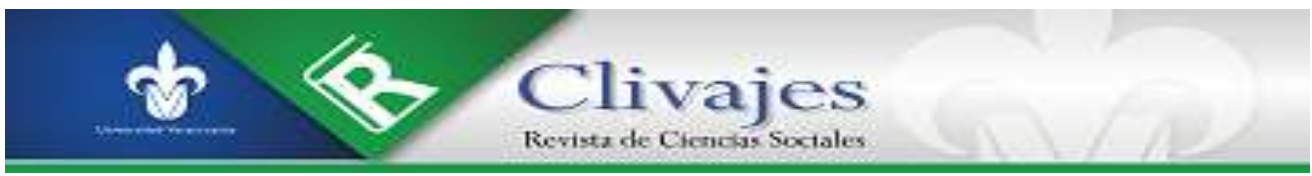

Eduardo Aristóteles Ramírez Martínez

EL RESPETO ENTRE LA POLÍTICA DE LA VIOLENCIA Y LA VIOLENCIA DE LO POLÍTICO. Un eSTUdio de CASO EN QueRÉTARO, MÉXICO

Clivajes. Revista de Ciencias Sociales. Año VII, número 13, enero-junio 2020, pp. 53-79. https://clivajes.uv.mx/index.php/Clivajes/editor/proofGalley/2649/4461 Instituto de Investigaciones Histórico-Sociales, Universidad Veracruzana

Clivajes. Revista de Ciencias Sociales/ISSN: 2395-9495/IIH-S, UV/Xalapa, Veracruz, México

Recibido: 27/11/2019

Aceptado: 10/12/2019

Dictaminado: $17 / 03 / 2020$ 


\title{
EL RESPETO: ENTRE LA POLÍTICA DE LA VIOLENCIA Y LA VIOLENCIA DE LO POLÍTICO. UN ESTUDIO DE CASO EN QUERÉTARO, MÉXICO
}

\author{
Eduardo A. Ramírez Martínez*
}

\section{Resumen}

A partir de un estudio de caso en Querétaro, se propone entender y mostrar la violencia de los jóvenes como forma inesperada de manifestación de lo político. Por un lado, los jóvenes son víctimas de la violencia del seno familiar, de las políticas gubernamentales y de la incomprensión del mundo adulto. Todo ello se vive como falta de respeto. En este contexto, los jóvenes utilizan la violencia para hacerse del respeto demandado y lo político surge, entonces, en un doble y paradójico sentido: como construcción de una comunidad externamente negacionista y violenta, y, a la vez, internamente creativa, dialógica y solidaria.

En su referencia externa, la comunidad precisa la oposición amigo-enemigo, lo cual recoge el sentido que Carl Schmitt atribuyó a lo político, pero en su veta interna, la comunidad necesita de diálogo, entendimiento y una política que afirme los rasgos comunes por encima de los diferenciadores, más a la manera como Hanna Arendt concibe lo político. En este doble juego, los jóvenes de Menchaca ganan respeto y restituyen los déficits de afecto, reconocimiento y solidaridad perdidos en sus comunidades políticas de origen: el Estado, la familia y su propio barrio.

Palabras clave: Comunidad, Violencia, Respeto, Lo político, Instituciones

\section{INTRODUCCIÓN}

El estado de Querétaro no figura en el escenario nacional por violencia del crimen organizado; sin embargo, la situación delictiva y de violencia ha venido empeorando consistentemente en el municipio capital. ${ }^{1}$ Por diversas vías, los jóvenes constituyen un sector particularmente inmerso en dicha problemática. Ante ello, vale la pena echar un vistazo a la relación entre jóvenes y violencia, pues consideramos que, además de ser difícil de enfrentar, la situación tiene potencialidades políticas.

Exploramos esta posibilidad en la colonia Menchaca II, la cual se caracteriza por sus problemas de violencia y delincuencia. La colonia fue azotada, de 2015 a 2018, por

* Profesor-investigador, coordinador de la Licenciatura en Gestión Pública y Gobierno en la Universidad Autónoma de Querétaro (UAQ). Es doctor en Estudios Interdisciplinarios, maestro en Ciencias Sociales, especialista en Partidos Políticos y Procesos Electorales, y licenciado en Ciencias Políticas y Administración Pública por la UAQ.

1 Sobre homicidio doloso en México y particularmente en Querétaro, consúltese: https://n9.cl/xzur, https://n9.cl/po4a. 
una ola de delitos y otras formas de violencia. ${ }^{2}$ En el imaginario queretano, esto reavivó la imagen de un territorio peligroso y violento. Al acercarnos más, pudimos constatar los problemas, pero sobre todo la aparición de dos elementos: la proliferación de riñas y enfrentamientos entre grupos y pandillas juveniles y la demanda de respeto por parte de éstos. Entrevistamos a algunos de los jóvenes integrantes de pandillas y les preguntarnos cuál era la razón de las constantes riñas y agresiones; su respuesta fue contundente: "Yo creo que por respeto, ¿no?”.

Durante los recorridos que paralelamente hicimos por la colonia, en las miradas y conversaciones de los jóvenes, en el grafiti y la vandalización de la infraestructura fueron muy notorios el enojo, la tristeza, el consumo de drogas; de ahí que nos planteemos, ¿cómo se relaciona la violencia con la demanda de respeto y la proliferación de grupos juveniles?, ¿tiene esta violencia posibilidades políticas o es un mero síntoma de descomposición social?

Los jóvenes son violentos porque han sido violentados (Reguillo, 2008). Están enojados, decepcionados y tristes. Ante ello, situamos el fenómeno de la violencia juvenil en un momento de debilitamiento del modelo de justicia social previo al que rige actualmente (Buffington, 2001; Garland, 2005; Wacquant, 2009; Castel, 2010; Bauman, 2011). A pesar del éxito económico de la capital queretana y de las políticas focalizadas del periodo, los jóvenes de ciertos sectores tienen problemas para integrarse.

Tal éxito económico no está exento de paradojas y contradicciones, pues los jóvenes de los sectores sociales medio y bajo tienen pocas oportunidades de movilidad, sufren precariedad laboral y, en general, de bajas expectativas de inserción laboral exitosa (Carrillo, 2017). Además, las nuevas políticas para los jóvenes poco se distancian del prejuicio y el estigma, la reeducación, el punitivismo; sobre todo, están basadas en la incomprensión del sector (Ramírez, 2019).

Las dificultades no terminan ahí. La familia, otrora fuente de protección (económica, afectiva y social) y solidaridad, vive un conjunto de tensiones que merman su capacidad protectora y solidaria (Sunkel, 2006), y también exhiben su rostro más dramático en la violencia interior. Esta nueva condición de la familia trastoca los soportes económicos y afectivos de los jóvenes, arrojándolos a una condición de soledad y franca vulnerabilidad.

Sin embargo, la violencia que los jóvenes viven poco nos dice acerca del significado de la violencia que utilizan. Aunque el fenómeno es muy llamativo,

\footnotetext{
${ }^{2}$ Para más detalles: https://n9.cl/nxh2.
} 
consideramos que la violencia es el último momento de un proceso de construcción política más complejo y al que denominamos "creación de comunidad". Cuando estos jóvenes forman grupos, que algunos de ellos llaman "pandillas", lo que en realidad están formando son comunidades y un orden social paralelo, y de pequeña escala (Reguillo, 2005), con rasgos de creatividad cultural, que implica un entretejido de símbolos, creencias e interacciones, como respuesta semejante a la violencia (Burgois, 2010) y también una forma particular de habitar el espacio creándolo (Perea, 2007).

La comunidad creada permite a los jóvenes ganar respeto, al interior y al exterior, les aporta la posibilidad de recuperar un poco de la solidaridad y certidumbre perdida, mientras que la violencia se convierte en el medio ideal para defender esta comunidad. La violencia no sólo es destrucción o agresión física, sino también la invención de un relato que da vida a la definición de la oposición amigo-enemigo, que es útil principalmente al exterior y exhibe la mecánica de "lo político" de Carl Schmitt (2009). ${ }^{3}$

Al interior, la invención de la comunidad tiene un sentido político más creativo, menos violento, con claras posibilidades políticas, a la manera de Hanna Arendt (2009). Implica la creación de reglas, la posibilidad de diálogo y, sobre todo, el intento de recuperar el afecto, el reconocimiento y la solidaridad perdida.

Esta propuesta nos enfrenta a la necesidad de comprender la creación de la comunidad y reconstruir su significado político, a partir del reconocimiento de la experiencia de sujetos concretos en el territorio; sujetos que, a su manera, dialogan con la violencia que pesa sobre ellos y descubren, y crean cierto resquicio para ser agentes.

Reconstruir la experiencia nos ha llevado a utilizar todas las fuentes que pueden abonar a esta tarea: lo mismo datos censales, que la opinión de funcionarios y espectadores; con especial énfasis hemos dialogado y observado, en distintos momentos, a los protagonistas. No ha sido sencillo, pues son desconfiados con los extraños, pero nos hemos acercado a algunos que se han abierto, particularmente estudiantes de secundaria. ${ }^{4}$

\footnotetext{
${ }^{3}$ En este sentido, Reguillo (2005) observa a los jóvenes en la paradoja de víctimas o victimarios; pensando en las violencias, la autora las concibe como formas con las que los jóvenes se reapropian y empoderan ante procesos estructurales de desafiliación.

${ }^{4}$ Para este trabajo, entrevistamos a tres docentes y siete jóvenes (cuatro hombres y tres mujeres) de la Escuela Secundaria de Menchaca II, así como a dos jóvenes de esta colonia; asimismo, tuvimos dos sesiones de trabajo con un grupo de adultos mayores. Las edades de los jóvenes oscilan entre los 13 y los 18 años. Los profesores nos indicaron qué jóvenes podían hablar y resultarían clave por su cercanía - protagonismo- con la violencia. Además, hicimos varios recorridos, observando el estado de la infraestructura urbana, las viviendas y los lugares de reunión. También entrevistamos a tres oficiales de policía, encargados de los rondines a la colonia en ese lapso. Durante la realización del programa "Pinta tu Sueño" - ejecutado por el municipio de Querétaro, como parte del Programa Nacional de Prevención de la Violencia y la Delincuencia (PRONAPRED)-, observamos el desarrollo de algunas sesiones y conversamos con dos de los ejecutores del programa.

El trabajo de campo se llevó a cabo de 2016 a 2018, como parte de la tesis doctoral del autor.
} 
Hemos buscado comprender la violencia, no sólo en el sentido explicativo de por qué surge, sino sobre todo por lo que anuncia. En esta labor, hemos comenzado por la violencia que los jóvenes protagonizan en el barrio; sin embargo, en el camino hemos descubierto que esta no es la primera, sino la última pieza del rompecabezas. Recurrimos al análisis de situaciones sociales para indagar en las experiencias y los significados, lo que nos llevó a tocar, paralelamente, sus enfrentamientos con grupos rivales, el sentido del grafiti y la vandalización, así como su relación con la autoridad, los vecinos y las familias.

Según Gluckman (1958), las situaciones sociales son acontecimientos a partir de los cuales es posible abstraer la estructura social, las relaciones y las instituciones sociales. A esta estrategia le hemos dado un uso particular, diferente al uso típico de la disciplina antropológica. ${ }^{5}$ En el caso de los antropólogos, obliga a una descripción densa de los acontecimientos seleccionados; sin embargo, no hemos andado el mismo camino, sino que generamos una reflexión con los actores a partir de tales acontecimientos. En adelante, citaremos algunas de las reflexiones que ilustran este argumento.

Tenemos razones para esto. Por un lado, nuestro interés principal no fue describir los acontecimientos, sino extraer las maneras en las que la gente los piensa, valora y concibe; por otro, al tratarse de acontecimientos relacionados con la violencia, nuestra integridad física resultaba comprometida.

Este trabajo está dividido en tres partes; en la primera, hacemos un recorrido por las características del territorio, enfatizando cómo se presenta la violencia sobre los jóvenes; en la segunda. Hacemos una propuesta teórica para comprender cómo se muestra lo político en la violencia protagonizada por los jóvenes; sobre lo anterior, en la tercera, analizamos el programa gubernamental "Pinta tu Sueño" para comprender qué significa la violencia y cómo se expresa.

\section{VIOLENCIA Y FALTA DE RECONOCIMIENTO SOBRE LOS JÓVENES DE MENCHACA II}

De 2015 a 2018, en Menchaca II se registró un incremento de la violencia y el número de delitos: enfrentamientos entre grupos juveniles, crímenes constantes de la pandilla de "El Danser" y choques con la policía coparon el territorio. ${ }^{6}$

\footnotetext{
${ }^{5}$ Gluckman (1958) define: "una situación social [como] el comportamiento, en cierta ocasión, de miembros de una comunidad como tal, analizado y comparado con su comportamiento en otras ocasiones, de tal forma que el análisis revele el sistema subyacente de relaciones entre la estructura social de la comunidad, las partes de la estructura social, el ambiente físico y la vida fisiológica de sus miembros”.

${ }^{6}$ Aunque no hay datos públicos, los habitantes, los policías entrevistados y los medios de comunicación consultados confirman el incremento de la violencia.
} 
La colonia Menchaca II se ubica en la periferia norte del municipio de Querétaro. Gracias al avance de la industrialización, durante las décadas de 1970 y 1980, el ejido se fue urbanizando y habitando, irregularmente, por población llegada de otros municipios del Estado. Hay infraestructura urbana, pero lo accidentado de la geografía, la situación irregular de no pocas viviendas y la vandalización hacen que la capital se encuentre en malas condiciones. El territorio combina calles pavimentadas, empedradas y de terracería.

La mayoría de las viviendas tiene terrenos amplios y servicios básicos, pero las construcciones son pequeñas, la mayoría modestas y hechas de materiales variados; no pocas tienen techos de lámina y patios con piso de tierra y muchas están abandonadas y vandalizadas. Según el censo 2010, en Menchaca II habitan 3744 personas; 1852 hombres y 1884 mujeres; 2021 personas de entre 0 y 24 años de edad y 104, de 65 o más años de edad, lo que muestra que más de la mitad de la población es joven.

En la colonia, hay tres planteles escolares públicos: un preescolar, una primaria y una secundaria. La asistencia escolar de los jóvenes es un problema; de los 278 jóvenes de entre 15 y 17 años, sólo 140 asisten, mientras que de 572 jóvenes de 18 a 24 años, asisten sólo 64. Esto se corrobora en las entrevistas con docentes y estudiantes de la secundaria, quienes hablan de lo habitual que resulta el abandono de los estudios, así como las bajas expectativas y dificultades de los jóvenes para continuar en la escuela. Cuando se les entrevista, su expectativa de vida implica una crítica difusa: "quedarse en el barrio o con la banda", como si no hubiese un plan de vida, pues muchos quieren abandonar la escuela.

Aunque no tenemos datos precisos sobre ocupaciones y remuneraciones, con base en el trabajo de campo realizado, podemos decir que entre los habitantes de la colonia en estudio predomina el trabajo en fábricas y oficios como albañilería, mecánica y herrería, lo que nos hace intuir malas remuneraciones y empleos precarios. La precariedad se refleja, entre otras cosas, en la situación de derechohabiencia, pues 1357 empleados tienen cobertura del Instituto Mexicano del Seguro Social (IMSS) y 1 094, del Seguro Popular (SP).

En general, en las entrevistas realizadas, la situación de la familia se concibe como un problema grave, que va desde la ausencia prolongada de los padres (por razones laborales), las carencias, el abandono de los hijos, hasta la violencia intrafamiliar. Al 
respecto, aunque hay carencias económicas ${ }^{7}$, lo que más afecta a los jóvenes es la desprotección y vulneración que viven por su situación familiar, la cual representa una fuente de carencias, abandono y un escenario cotidiano de violencia.

Narrando la situación familiar de un amigo, "El Nepo" dijo que "había un chavo que siempre traía más dinero que yo, y su hermano, pues sabíamos que andaba de ratero y después terminó en la cárcel porque mató a un chavito”. Si algo pasa en colonias como Menchaca II, es “culpa de las mamás” (sentimiento de culpa), “algunas sienten que es muy injusto lo que les pasa [...], sienten que es algo..., que no se merecen lo que les pasa con los hijos [...]. La característica principal de ellas es que tenían que trabajar, descuidaban los hijos, y para ellas es lo mejor que podían hacer".

En las entrevistas con el grupo de adultos mayores y docentes de la secundaria del lugar, destacó la constante intervención del Sistema para el Desarrollo Integral de la Familia (DIF) para atender a niños, adolescentes y mujeres violentados al interior del núcleo familiar. Al respecto, cuando "El Nepo" nos contó su experiencia con amigos que empezaban en la ruta delictiva, afirmó que:

Ellos tienen mucho resentimiento, no sé; cuando era día de la familia, se burlaban de mí, porque íbamos a comer o salíamos con mi familia y se burlaban un montón de mí, pues, porque ellos, pues no había con quien festejaran [...] es bien evidente el enojo de ellos.

Los problemas al interior del seno familiar son el elemento clave para entender el cúmulo de sentimientos, conductas y violencia que se ciernen sobre el territorio de Menchaca II; sin embargo, no es el único, pues también perciben estigmatización e incomprensión cuando buscan trabajo o se implementan programas gubernamentales. ${ }^{8} \mathrm{El}$ abandono y esta trayectoria familiar problemática se combina con la escasez de recursos, lo cual potencia el consumo de drogas, la violencia y los delitos. Entre algunos de los jóvenes entrevistados, abundan las referencias al uso de drogas: "para no sentir hambre”, pero también usan drogas: "para no sentir, por ejemplo [...] depresión por los problemas en casa".

Además, el consumo de drogas se relaciona con una especie de solidaridad atomizada y negativa; de hecho, tanto el uso de drogas como el de ciertas vestimentas y referencias a sectores particulares del barrio forman parte de la identidad de las

\footnotetext{
${ }^{7}$ Por sus niveles de marginación y grado de rezago social, Menchaca II es considerada Zona de Atención Prioritaria (ZAP). Su índice de marginación urbana oscila entre alto y muy alto, dependiendo del sector de la colonia y del rezago social que se padezca; este último va de bajo a alto, dependiendo también del sector.

${ }^{8}$ En las entrevistas, abundaron las referencias a problemas para encontrar empleo por proceder de Menchaca II.
} 
numerosas pandillas que pueblan el territorio. Hay solidaridad, pero dividida entre muchas pandillas, y esta es la cotidianidad del ser joven y habitar en Menchaca II.

El Estado, por su parte, no goza de mejor reputación. El policía es el enemigo por excelencia, en virtud de sus constantes intervenciones $-\mathrm{y}$ abusos- sobre los jóvenes. ${ }^{9}$ El punitivismo se ha erigido como un importante componente de la política gubernamental implementada en el territorio (Ramírez y Belmont, 2017). Además, los programas de corte preventivo reproducen estigmas, pedagogía reeducativa y falta de reconocimiento.

\section{RESPETO, COMUNIDAD Y VIOLENCIA}

Como hemos mostrado, los jóvenes son objeto de violencia. Ahora bien, conviene entender qué significa la violencia e identificar los tintes políticos que, desde nuestra perspectiva, ésta tiene. ¿Cómo articular - a partir de un relato teórico que nos acerca a la comprensión de Menchaca II- elementos empíricamente observados, como la demanda de respeto, las muchas pandillas y la violencia en el territorio?

\section{Respeto}

Cuando los jóvenes hablan de que se les falta al respeto, exhiben una crítica moral hacia situaciones, instituciones y actores concretos. Demandar respeto es luchar y buscar la obtención de dignidad personal (Burgois, 2010), así como la consecución de estatus (Martínez, 2016). El respeto alude a la mirada del otro en dos sentidos; por un lado, como “acción de mirar atrás, de considerar y de poner atención” (García-Pelayo, 1988), lo que sugiere que el otro es capaz de mirar atentamente y con consideración. Así, el respeto es una demanda de reconocimiento, consideración, atención al trasfondo de una persona, lo cual lleva a la comprensión del joven en sus propios términos, minimizando el estigma y potenciando la solidaridad.

Por otro lado, el respeto implica no una mirada hacia atrás, sino hacia adelante. Refiere, entonces, la capacidad de valorar y honrar a otra persona por su potencialidad de futuro, aunque no se esté de acuerdo con sus acciones y valoraciones. Respeto es aceptar a la otra persona y no pretender cambiarla; es no juzgarla por sus actitudes, conductas o pensamientos. No se le reprocha ni se espera que sea de otra forma. Así, a demanda de respeto es en una lucha por el reconocimiento, en un medio social que poco considera la

\footnotetext{
${ }^{9}$ El abuso de los policías municipales fue una referencia constante entre los jóvenes entrevistados.
} 
trayectoria y necesidades de los jóvenes, y no los valora en sus potencialidades hacia el futuro.

La falta de respeto es leída por los jóvenes como la negación “del exterior” a dialogar con ellos, en la medida que se les demanda adaptación a directrices y opciones que poco les resuelve y significa. Por eso es que no participan en los programas, y cuando lo hacen buscan transgredirlos o resignificarlos. Si esto es así, la posibilidad de pertenecer a la comunidad política, sea el Estado o la familia, se dificulta. Por lo tanto, esta cerrazón lleva a los jóvenes a tomar la decisión de construir su propia alternativa, que precisa de dos movimientos paralelos: destruir y construir. Tal como lo ve Honneth (2011), la lucha por el reconocimiento es, en realidad, la lucha por la comunidad.

En efecto, la demanda de respeto se traduce en la creación de comunidades de jóvenes, a manera de pandillas y grupos. ¿Qué es la comunidad y cómo funciona en términos del logro de respeto y restitución del afecto y de la solidaridad?

\section{Comunidad y violencia}

La pandilla es una forma de comunidad y resulta funcional para ganar respeto y restituir afecto y solidaridad (Ballesteros de Valderrama et al., 2002). Crear comunidad es crear un orden propio y alternativo. Tiene límites, reglas, prácticas y una doble funcionalidad, claras a partir del adentro y del afuera. Aunque es un algo integrado, el juego adentro/afuera lleva a implicaciones distintas.

La comunidad es un continuum entre el adentro y el afuera. Define un afuera que, en el caso de los jóvenes, los lleva a transitar de la crítica y demanda de respeto, a la creación de un enemigo común (el policía, el adulto, el otro), con argumentos que legitiman esta operación. Se basan en mostrar los peligros y amenazas provocadas por el enemigo, lo que justifica su negación, exclusión y hasta destrucción.

Al enemigo se le niega, se le transgrede $y$, al final, se le destruye; por eso es que si el enemigo dice: “vida”, el joven dice: “muerte”. Este es el momento en el que Carl Schmitt (2009) observa la creación de la oposición amigo-enemigo, como una clara política defensiva y negacionista. Eso explica por qué al policía se le atribuyen abusos, desproporción y estigmatización, no siempre tan frecuentes, o por qué hay un intento de anular, deslegitimar o negar al grupo rival, a través de la violencia, pintando sobre sus grafitis o destrozando "sus calles".

Tener un enemigo común, paradójicamente, mantiene y solidifica los lazos de amistad y solidaridad con los de adentro; refuerza el sentido de igualdad, pertenencia y, 
por lo tanto, funciona como la familia que se perdió o que tantos tristezas ha causado. El adentro de la comunidad formada, en cambio, precisa no negación, sino construcción (Arendt, 2009). Aunque la negación e intento de eliminación es una parte de lo político, aquí este segundo componente exalta la convivencia, los acuerdos y la construcción de alternativas.

Mientras que Schmitt (2009) ve en la política externa de la comunidad la expansión del territorio mediante la eliminación del enemigo, Arendt (2009) la ve como una expansión lograda a través del entendimiento mutuo, reafirmando lo común y no lo diferente. En Arendt la comunidad se expande por la asimilación dialógica con el otro; en Schmitt, la comunidad se expande por la eliminación del enemigo. En el caso de los jóvenes, es interesante cómo se manifiesta el doble juego, Schmitt-Arendt. Hacia afuera, el lado schmittiano se manifiesta en un política expansionista, negacionista y violenta, pero al interior, en el lado arendtiano, priva la construcción de reglas de entendimiento mutuo. La comunidad es un tipo de orden social alternativo que funciona como un muro al exterior, pero como una polis al interior.

Aunque la violencia al exterior es un componente importante, la fuerza real de sus comunidades radica en la creación de reglas, acuerdos y prácticas internas, el munus que observa Espósito (2012). Es aquí donde radica la inmunidad frente a lo externo y lo que da su carácter proactivo a las comunidades. Hacia adentro, la comunidad no define sujeto u objeto, sino relaciones, reglas y prácticas, en donde es posible distinguir y construir diferentes formas de reconocimiento, tales como el amor, la amistad, el honor, la dignidad, los derechos y la solidaridad.

En su comunidad, los jóvenes crean su propia utopía, en un intento por construir, entre lo imaginario y lo real, un orden social diferente, con el potencial de dar la vuelta al que los ha violentado. El grupo, la pequeña comunidad, representa el ideal de invulnerabilidad por excelencia. Entonces, si la comunidad al interior ofrece esto, vale la pena pelear y hasta dar la vida por el grupo que habita la comunidad. Así, la violencia al exterior es el instrumento que asegura a los jóvenes el respeto, pero el entendimiento al interior les asegura inmunidad, esto es, seguridad y restitución de lo perdido en la familia, ante la falta de oportunidades y en la violencia de la acción estatal.

Las concepciones clásicas de la comunidad aluden al sentido de pertenencia y a la identidad, pero carecen de fuerza en la medida que no ven en esto un sentido político de defensa y respeto de lo propio frente a lo extraño. La identidad y el sentido de pertenencia no son otra cosa que formas de construir muros de respeto, a partir de densas y casi infranqueables murallas sociales. 
La comunidad también puede ser pensada como una respuesta crítica y creativa frente a la violencia de las instituciones, pues representa la desarticulación de formas de comunidad o consenso. Si bien es cierto que en el imaginario colectivo y jurídico dominante las instituciones constituyen ámbitos de igualdad, recordemos que la desprotección, engendrada por la ruptura del estado de bienestar, ha hecho del Estado actual o neoliberal una comunidad de la desigualdad, con lo que, en estricto sentido, debería de cuestionarse dicho estatus. Actualmente, por ejemplo, ya no es posible hablar de una comunidad nacional.

\section{LA COMUNIDAD AL INTERIOR: LA POLÍTICA AUTOAFIRMACIONISTA}

La política permite la comunicación y la acción. Según Arendt (2009), la política es el mundo de la igualdad entre los hombres y sólo es posible en el reconocimiento de que se es parte, de que se forma parte de algo común, esto es, de una comunidad; es entendimiento comunicativo y acción constructiva.

En una primera aproximación al concepto de política, en Arendt está vinculado a lo que emerge o aparece cuando los hombres se encuentran para tratar asuntos comunes a partir de la palabra y la acción. El discurso permite presentarse ante los otros y establecer (y/o aceptar) un espacio compartido, un lugar común, público, en el que se respeta la pluralidad y puede surgir algo nuevo, manifestación de la libertad humana. Ahora bien, para avanzar en el entendimiento de esta concepción, es preciso establecer la distinción entre poder y violencia, que se asocia con su idea de acción.

El poder surge allí donde los hombres, en condición de igualdad, se encuentran y ligan a la política, puesto que ésta tiene la pretensión de desarrollarse en un marco de diálogo concertado, de persuasión y reconocimiento, orientado a la acción mancomunada -no exenta de tensiones. La política, de este modo, recupera su dimensión plural y contingente, ya que en el espacio público, las decisiones no están determinadas ni tienen un contenido prefijado. Recordemos, desde luego, que es un nuevo espacio público. La igualdad de los miembros, como participantes de la polis, para tener voz y ser escuchados es la condición de posibilidad para la conformación de ese espacio público. La comunidad es una especie de polis, pequeña y nueva, por sus pretensiones y posibilidades de fundar un orden.

El objetivo de esta política es generar estrategias de protección que, en cierta medida, permitan negociar con agentes externos, considerados poseedores de los recursos, y den la posibilidad de consensuar que tales recursos sean estratégicamente 
utilizados, pues los agentes gozan tanto de legitimidad como de fuerza para aglutinar voluntades. La obediencia del territorio está en juego en la medida en que el gobierno acepte o la negociación, es decir, que reconozca la legitimidad de las demandas.

En contraste, el no reconocimiento constituye la antesala a la desobediencia, y se manifiesta como el no respeto a legalidad -las reglas del orden hegemónico- y la tolerancia a la ilegalidad, el delito, la ausencia de participación y la disminución o cancelación del diálogo. Esta posibilidad implica que la comunidad se contraiga, como estrategia para propiciar el diálogo y la negociación en nuevas condiciones.

En este sentido, el delito no es tanto una manifestación de la precariedad económica, sino una crítica a la violencia y, al mismo tiempo, un intento por recuperar la atención del Estado y la familia para favorecer un nuevo arreglo, pues, ante todo, la ruta autoafirmacionista implica la negociación del orden: al interior, esta negociación supone la igualdad entre los miembros de la comunidad o "firmantes del consenso", pero al exterior supone también cierta pretensión de igualdad.

\section{LA COMUNIDAD AL EXTERIOR: LA POLÍTICA NEGACIONISTA}

El orden negacionista representa lo opuesto al orden anteriormente descrito; en él predominan, al exterior, la confrontación y la negación del otro, mientras que al interior imperan las relaciones jerárquicas y de solidaridad. Así, el respeto se obtiene a partir de la certidumbre y protección de las jerarquías y la solidaridad, así como del sentido y los alcances de la oposición amigo-enemigo cuyos polos se retroalimentan.

A diferencia de lo que ocurre en el orden autoafirmacionista, en éste, el respeto es una cuestión interna. No quiere decir que no haya referencia o relación con el exterior, sino que no se funda en la posibilidad de la negociación ni la relación con el otro: se funda más bien en el ensimismamiento, la negación del otro y, a veces, hasta en la eliminación del otro. Cerrarse significa la posibilidad de cortarle el paso a los agentes vulnerantes, siempre de carácter externo.

Al interior, el grupo representa la posibilidad de recuperar lo perdido, de revertir aquello que lo ha vulnerado y ha sido fuente de inseguridad: el abandono y la violencia de la familia y el Estado, la falta de reconocimiento (respeto) social. El grupo es fuente de reconocimiento y solidaridad; ahí se establecen relaciones fraternales y de afecto.

En este orden negacionista, luchar por el respeto es básicamente una cuestión interna, pero la fuerza del orden interno pasa por una férrea manera de hacerle saber a los de afuera que hay un orden sólido al interior. Así, la relación con el exterior, siempre 
referida al orden interno, es de confrontación y transgresión. Al exterior, ganarse el respeto pasa, en gran medida, por la confrontación de los opuestos amigo-enemigo. En el caso de este orden, tal oposición no es un recurso usable en el mercado, sino el anuncio de un orden social distinto, con pretensiones de ser infranqueable.

Lo anterior es una manera de relacionarse con el otro (externo) sin una intención real. Refleja un tipo de conflicto que, por insoluble, desborda el orden hegemónico y, por lo tanto, difícilmente acepta mediaciones o controles institucionales. Es la búsqueda de separación de dos órdenes considerados distintos, que se objetiva en discursos, prácticas y reglas que señalan quiénes y por qué son los amigos y quiénes y por qué son los enemigos. Son reglas y prácticas que indican quiénes están fuera y quiénes dentro de un orden. El respeto a las reglas garantiza la convivencia armónica en el territorio.

La distinción "amigo y enemigo" es a la política, lo que lo bueno y malo a la moral, y lo bello y feo a la estética. Esta polaridad evidencia la imposibilidad de encuentro. La distinción amigo-enemigo indica el grado extremo de intensidad de una unión o una separación que puede subsistir teórica y prácticamente sin que, al mismo tiempo, deban ser empleadas otras distinciones morales, estéticas, económicas, etc., pues no hay necesidad de que el enemigo político sea moralmente malo o estéticamente feo: el enemigo es simplemente el otro que está en contra de mi posición.

El enemigo político es un conjunto de hombres que se combaten virtual o realmente y se contraponen a otro grupo del mismo género. Enemigo es sólo el enemigo público, puesto que todo lo que se refiere a semejante agrupamiento, y en particular a un pueblo íntegro, deviene público por ello mismo. Se puede decir que el antagonismo político es el más intenso y extremo de todos, y cualquier otra contraposición concreta es tanto más política cuanto más se aproxima al punto extremo, el del agrupamiento basado en el concepto amigo-enemigo.

El criterio amigo-enemigo, planteado por Schmitt (2009), como expresión de la necesidad de diferenciación, conlleva un sentido de afirmación de sí mismo (nosotros), frente al otro (ellos), lo cual implica que tiene un fuerte componente identitario. Así pues, es posible observar el contenido positivo de la relación amigo-enemigo como conciencia de igualdad y de la otredad, la cual se define marcando al grupo, entre otros de los que se distingue con base en ciertos referentes.

La diferencia que supone el nosotros-ellos establece un principio de oposición y complementariedad. La percepción que un grupo desarrolla de sí mismo en relación con los otros es un elemento que lo cohesiona y distingue al mismo tiempo. Reconocer al enemigo es identificar un proyecto que produce un sentimiento de pertenencia, pero 
también uno que genera repulsión. Identificar al enemigo, o sea, a quien encarna y causa la repulsión, es un elemento de protección. Si se nombra a un enemigo, surge una conciencia crítica y articulada, en la medida que es compartida por la comunidad. También, en este poder de nombrar el enemigo, se establecen las prácticas adecuadas para contenerlo o enfrentarlo.

Schmitt (2009) afirma que la esencia de lo político no puede ser reducida a la enemistad pura y simple, sino que abarca la posibilidad de distinguir entre el amigo y el enemigo. El yo, entonces, se define y representa en el nosotros. El otro se define por su extrañeza y diferencia. La existencia del otro, paradójicamente, mantiene la vitalidad del nosotros, al mismo tiempo que la ha engendrado. Implica la construcción de un conjunto de prácticas que precisan del uso de marcadores simbólicos que exalten las diferencias y distancias frente a los otros. Como diría Dubet (2010) para el caso de los grupos de jóvenes: "deben su estabilidad únicamente a la construcción de una oposición más o menos caliente contra otros grupos: las bandas exigen una 'guerra' aunque sea fría” (p. 104).

En este orden de ideas, la distinción amigo-enemigo lleva a la consideración de la violencia como uno de sus elementos más importantes. Digamos que la violencia es una consecuencia natural del nivel de confrontación supuesto en ese orden, sin embargo, tiene un doble sentido: al interior supone la garantía de mantener vigentes las reglas, pero también de asegurar el respeto de los miembros del grupo -ambos elementos, son condición para la continuidad del orden-, mientras que, al exterior, la violencia supone la dosis necesaria de transgresión para expandir las fronteras del orden que se ha instituido. Por ello, el delito siempre es hacia los otros y la violencia es casi inseparable del delito, a la vez que la posibilidad de expandir las fronteras permite que al interior se refuerce la legitimidad de las reglas y los liderazgos.

Empecemos por las implicaciones internas de la violencia. Aunque la violencia pueda ejercerse dentro o fuera del grupo, siempre es un acto de preservación del orden: la violencia lo reproduce. Los antropólogos han encontrado que la violencia es eficaz evacuando las amenazas que podrían romper el orden; esta es la violencia que se mantiene a través del rito (los medios simbólicos) y del derecho (normas, reglas, leyes).

Si la oposición amigo-enemigo es el deseo de diferenciarse de los otros, este deseo lleva a los grupos a establecer una fuerte competencia que les exige la construcción de diferenciadores. En este camino, las prácticas más reconocidas serían justo las que marquen las distancias. Los diferenciadores pueden ser cierto tipo de prácticas, pero también violencia. Ser el más violento, como búsqueda de diferenciación, asegura el 
respeto interno y externo. Al interior, la violencia asegura el respeto de los miembros del grupo, ya sea ejerciéndola ritualmente o hacia afuera con los iguales.

En el pensamiento de Schmitt (2009), la violencia juega un papel fundamental para la construcción del orden; es un momento político fundamental para mantenerlo. Ciertamente, Schmitt piensa la violencia en la lógica de lo político estatal y, en ese sentido, la policía y todo el aparato jurídico coercitivo constituyen los cuerpos estatales que ejecutan la tarea de la preservación del orden a través de la violencia.

Ahora bien, si seguimos por la ruta que abre Schmitt, es menester preguntarnos qué podría expresar, en lo político social, lo que representa la policía a nivel de política estatal. Si para el Estado la policía es el intento no político de recuperar el orden o suprimir el conflicto a través de la fuerza y la violencia - como negación de lo político--, ¿qué implica o exhibe la violencia para los grupos de jóvenes en nuestros territorios de estudio? ¿Es también una negación de lo político, como lo concibe Hanna Arendt?

Por increíble que parezca, al interior de los grupos, constituye una forma de diálogo con el nosotros. Sin duda, la violencia es también una forma de diálogo y reunión, no con los que se violenta, sino entre los que violentan. Al interior, la violencia es una forma política, con la que se está de acuerdo y partir de la cual se puede dialogar. Definitivamente, constituye la evidencia de un orden paralelo. La violencia es la partera del orden social, como lo apuntara Marx o como dijera Esposito (2012): "la sangre cimenta los muros de la ciudad”.

Una vez que se ha estabilizado el orden, es decir, cuando se ha obtenido el respeto, es necesaria su ampliación. La violencia también juega un rol decisivo en este momento, pues implica la dosis óptima para transgredir e invadir el orden social rival. Si no hubiera violencia, sería imposible expandir los límites del grupo. Esta expansión es una nueva posibilidad de instituir el orden. La violencia, entonces, puede considerarse como producto del poder de los hombres en reunión, pero, al menos implícitamente, tienen un objetivo: instituir o expandir un nuevo espacio público.

Ahora bien, el momento instituyente de la violencia requiere culminar con la institución de un espacio público estable, que sea el escenario de la aparición de los hombres en tanto iguales, un terreno propio de libertad. La violencia protege, en la medida que subvierte el orden preexistente y posibilita la expansión del orden nuevo. En ese sentido, los antropólogos han observado que todos los comienzos de las sociedades, de las civilizaciones y de los regímenes se asumen como periodos de violencia, pero una vez que la violencia ha tomado forma en las instituciones (técnicas, normas, ritos), se convierte en fuerza creadora. 
Sin embargo, al exterior, la violencia es la negación de lo político, la guerra y, por ende, la antesala de la destrucción; es el retorno al estado de naturaleza hobbsiano, en el que la existencia es brutal, breve y sin razón.

$\mathrm{Al}$ respecto, podemos afirmar que cuando hay violencia en un territorio, sea entre los habitantes o por parte del Estado en confrontación con los habitantes del territorio, lo que se está disputando es el orden, lo instituido o lo que se quiere instituir; es una disputa política, pero violenta. Es política en el sentido de anunciar un nuevo orden o la disputa por éste mismo, pero, al mismo tiempo, es la negación de la política. Sin duda, para muchos esta forma de disputarse el orden resulta profundamente desesperanzadora, como lo sería para la propia Hanna Arendt, pero existe y anuncia una manera en la que se pone en juego el orden que intenta propagar el Estado en los territorios.

Así pues, la violencia actual obedece, en primer lugar, a la ruptura del modelo de justicia social que detonó una crisis en el rol y capacidad protectora de las instituciones, generando una fuerte crítica social y, sobre todo, gestando un momento en el que los individuos, más o menos atomizados, buscan e intentan producir una comunidad, un orden, que les dé respeto. ¿Qué características asume en el territorio de Menchaca II?

\section{RESPETO, COMUNIDAD Y VIOLENCIA EN MENCHACA}

Como se ha establecido, la creación de comunidad es fundamental en la búsqueda del respeto. Las pandillas representan este intento de creación comunitaria, pues son "un sistema social organizado, gobernado por una estructura de liderazgo con roles definidos, que han sido legitimados. Ella sirve a funciones comunitarias y, como organización, no está envuelta en gran cantidad de violencia” (Jankowsky, 1991), aunque delito y violencia se usan en momentos concretos. ¿Cómo se forman la comunidades, qué reglas tienen y cómo se relacionan con el respeto en Menchaca II?

No existe un cálculo preciso sobre cuántas pandillas hay en Menchaca II. La policía identifica tres pandillas fuertes, mientras que los jóvenes entrevistados identifican cerca de veinte, si bien reconocen que muchas se crean y deshacen con facilidad. En las colonias aledañas, también hay pandillas y los enfrentamientos con las de Menchaca son frecuentes. Todo eso hace que cualquier cálculo resulte complicado.

Crear o vincularse a una pandilla es relativamente fácil, como lo muestra el testimonio del integrante de una de ellas: 
... del salón hicimos una banda; salió que nos empezamos a drogar, no todos; cada problema que salía, nos mandaban llamar e íbamos todos [...] si a uno lo agarraban, ahí íbamos todos a defenderlo. Pasaron muchas cosas. Ya después como que nos quería caer el veinte, de repente sí nos tranquilizábamos un momento, pero después llegaba otro tiempo en el que nos volvíamos a revelar, nos drogábamos, rayábamos.

Resulta significativo, sobre todo, el desarrollo del sentido de pertenencia; lo construyen de vínculos sociales estrechos, a manera de familia. El adentro es la garantía de pertenecer a una comunidad de valores, reglas y afecto; de hecho, son constantes las referencias a los compañeros de pandilla, como "mi carnal”.

La idea de grupo marca, ante todo, un ser y estar fuera. Es un conjunto de barreras sociales que le dicen a los miembros y a los no miembros cuáles son las reglas que deben respetarse para formar parte - para entrar- o para ser considerado una amenaza. El otro y el nosotros sólo son posibles en la medida en que hay reglas. Así, el otro se define por su diferencia y extrañeza. Se festejan y ritualizan las similitudes, pero también las diferencias; fiesta y rito generan cohesión, lo cual permite que el individuo encuentre solidaridad.

En Menchaca, pudimos observar, de manera general, que "el otro" representa una amenaza al respeto de los grupos juveniles; éstos significan lo que está fuera del grupo, en el sentido de no compartir la misma manera de apreciar el mundo (Marcial, 1998); son extraños y diferentes. La diferencia es amenaza y, en buena medida, se asocia "al otro" con la reproducción de la falta de respeto. El otro es fuente potencial de hostilidad. Se vive como incomprensión -y hasta agresión- a sus gustos, hábitos, consumos y preferencias; como una infravaloración. Por lo tanto, se enfrenta con resistencia y hasta con franca búsqueda de eliminación.

El otro, en buena medida, porta el germen del cambio y éste es tolerado en la medida en que la continuidad no se vea amenazada. La defensa de los valores, que son la expresión de la vitalidad interna, es fundamental para asegurar la continuidad. Se cambia sólo para preservar el núcleo más sólido de los valores. Cuando el cambio supone amenaza a los valores, entonces la movilización y defensa deviene lógica.

El cambio, con el germen de la amenaza, es desorganizador. Cuando el orden construido está bajo ataque, la movilización significa la defensa de la identidad, del grupo. A través de transformaciones y negociaciones, los grupos buscan mantener sus valores e identidad. Mantenimiento o cambio resultan útiles en la medida en que preservan la identidad, es decir, la continuidad de la sociedad, que da la continuidad con uno mismo. 
La violencia se convierte, así, en un aliado poderoso en dos sentidos. Primero, porque su uso busca acabar con el enemigo, esto es, con la fuente de falta de respeto. Es un mecanismo de sobrevivencia en un clima hostil, en el que impera la ley del más fuerte y hace que devenga natural la violencia; no obstante, también tiene la finalidad de reforzar los valores internos desmarcándose de otros grupos similares, pero vistos como competencia. Esto quiere decir que no es suficiente ser violento, sino que es necesario ser el más violento, porque esto refuerza la identidad (como posibilidad de diferenciación), las barreras del grupo: "los del Danser son unos hijos de su pinche madre, pasados de verga, hasta con las doñitas se meten, yo he visto cómo las han asaltado ahí en el hoyo". ${ }^{10}$

\section{Las pandillas a través de los grafitis ${ }^{11}$}
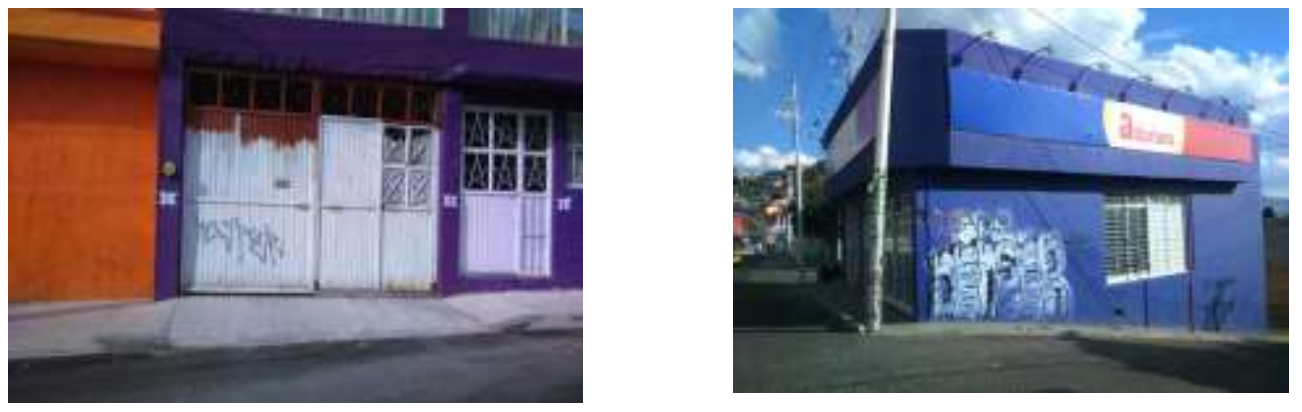

En el caso de Menchaca, los “otros” se encarnan en tres tipos de actores: "el que no es de la colonia" claramente se ve como una otredad lejana. En los recorridos por la colonia, pudimos notar que, cuando los jóvenes se percatan de una presencia que no es de ahí (fue una de las constantes en nuestro trabajo de campo), las miradas hacia el extraño son casi un reflejo instintivo y parecen buscar la intimidación.

Pero quizás una de las rivalidades más fuertes se da en contra de las "bandas de otros lugares o de otras calles" de la propia colonia. El que no es del "barrio" es claramente otro. Se ve como una fuente de amenaza al poder territorial que se ha conquistado. El territorio es el orden de seguridad por excelencia, de ahí que a las bandas rivales se les vea con enemistad, si bien se les ve como un "otro" contra quien se lucha en

\footnotetext{
${ }^{10}$ Esto dijo un joven aludiendo a la pandilla presumiblemente más violenta.

${ }^{11}$ Las imágenes muestran grafitis de dos de los grupos rivales en Menchaca II. Las fotografías son de la misma calle y según las entrevistas a estudiantes de secundaria, los episodios más violentos, protagonizados por las pandillas de "El Denser y la del Kasper”, ocurrieron por el dominio de esa calle.
} 
igualdad de circunstancias (Marcial, 1998). No sólo representa una amenaza al poder de controlar las acciones en el territorio, sino que puede significar una eventual pérdida de territorio, lo que asimismo implica la pérdida del respeto del líder o del grupo:

- No vamos a permitir que esos putos entren al barrio.

- ¿Por qué no?

- Porque son de otro barrio. Pinches chilangos, siempre que hemos ido a su barrio nos quieren tumbar, por eso aquí se la pelan [...] allá es suyo, pero aquí es nuestro. ${ }^{12}$

Perder el territorio es perder el orgullo, el respeto; la fuente de seguridad. Adueñarse del territorio es controlar el espacio y la garantía de que quien ingrese debe respetar los códigos. Esta enorme barrera desincentiva el acceso pacífico, por lo que la violencia, sea para traspasarlo o dominarlo, se vuelve fundamental. El orden es cerrado, intransigente, invulnerable, seguro.

El grafiti es además un medio con el que se marca el territorio o se exhibe ante los otros quién es el propietario. Las pintas sobre otros grafitis exhiben la conquista del rival y el eventual arrebato de su territorio. En algunas calles, los grafitis con el nombre de la pandilla de la zona están, incluso, pintados sobre la señalética oficial que da nombre a las calles, lo cual pareciera representativo del sentimiento de confrontación con la autoridad, con lo establecido, con lo que no los reconoce.

\section{Anulando al enemigo}

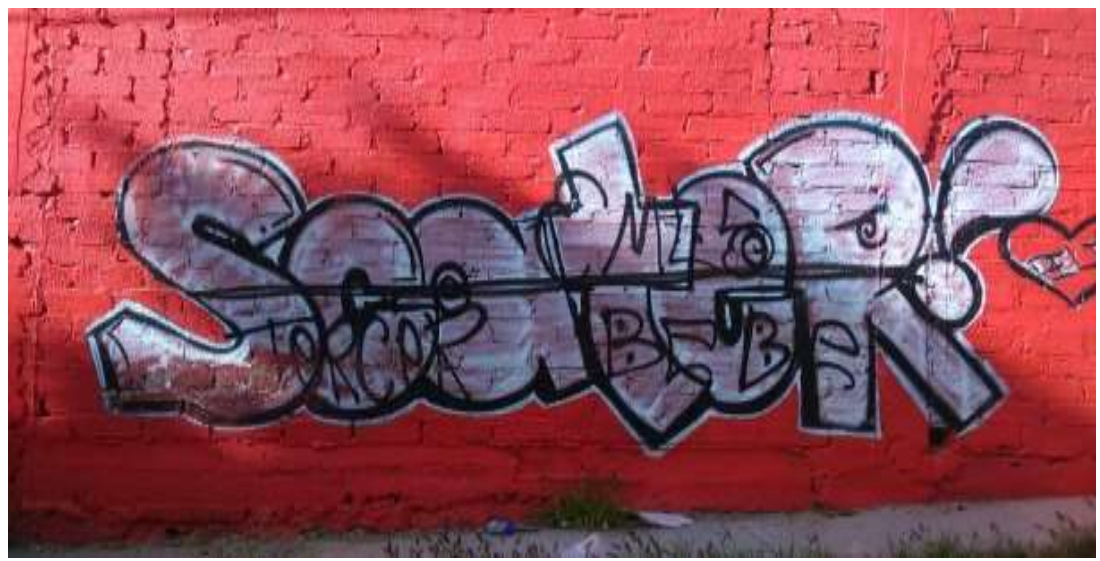

\footnotetext{
Pedrito Peñuelas.
}

${ }^{12}$ En entrevista, un joven mencionó esto en relación con la banda de "Los camellos" de la colonia aledaña, San 
En opinión de Dubet (2010): "las bandas son un intento de recrear vínculos solidarios, pertenencias sólidas, aportan a los miembros seguridad emocional y orgullo, mantienen relaciones hostiles con otras bandas para soldar a los individuos entre s'”. En este sentido, cualquier figura de autoridad se ve como un enemigo potencial, pero el enemigo histórico, sin duda alguna, es el policía.

En las entrevistas realizadas, las referencias a agresiones a los policías (patrullas apedreadas) también son constantes. La animadversión contra la autoridad, se observa, asimismo, en los muchos calificativos contra ellos y en las miradas de agresividad y desafío de los jóvenes cuando presencian el arribo de los policías. En 2017, se reportaron dos casos de agresión física contra policías.

Además de la lejanía práctica y simbólica de la autoridad con la gente, las acciones arbitrarias y punitivas de la policía han potenciado la resistencia y animadversión. Los testimonios reflejan que los jóvenes han sufrido y sienten haber sufrido todo tipo de agresiones por parte de los policías. Detenciones arbitrarias, encarcelamientos por faltas administrativas, discriminación por aspecto físico e indumentaria y muy frecuentemente por consumo drogas.

\section{El policía en Menchaca II}

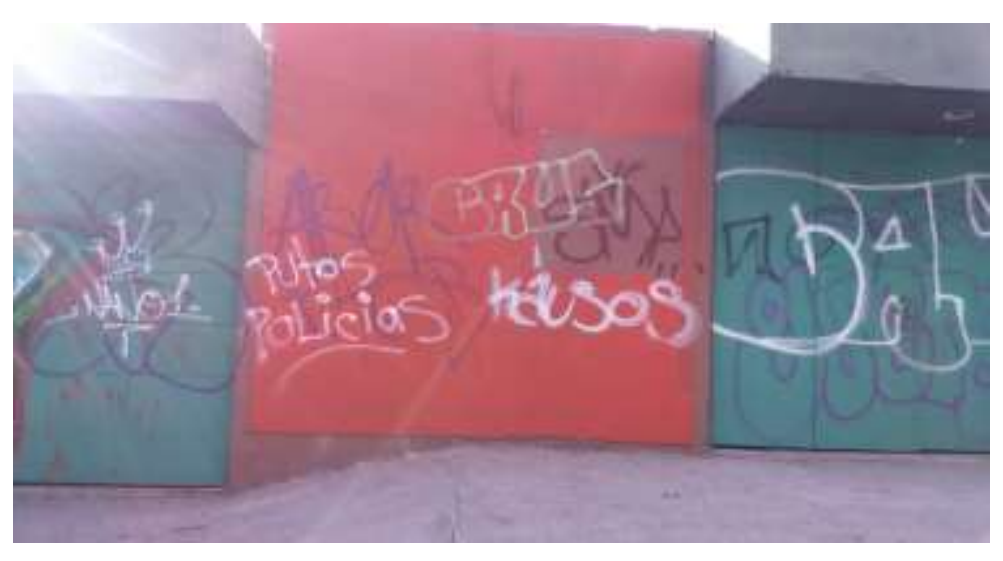

Entre las obras participantes en el programa gubernamental "Pinta tu Sueño", observamos un conjunto de alusiones a la violencia, la tristeza y la muerte, que reafirman la identidad "subversiva y negativa" juvenil, frente a la autoridad que instrumentó el programa, como se muestra en la siguiente fotografía. 


\section{¿Pinta tu sueño?}

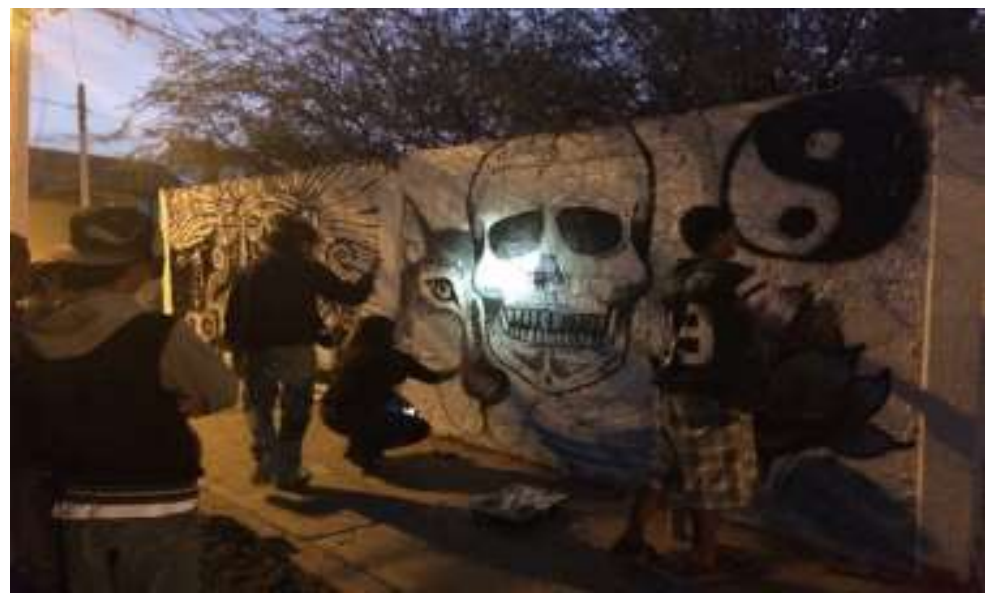

Las pandillas han construido un orden propio. Ese es su ámbito de respeto. Lo ajeno es combatido, pero también traducido, sometido a su orden. En este sentido, el grupo que pacíficamente trabajó los murales, lo hacía bajo los efectos del alcohol y la mariguana, y fue ayudado también por adultos que entraban a la misma dinámica de pintar y consumir droga y alcohol. Grafitear bajo los efectos de las drogas forma parte del orden del lugar, lo cual pone en tensión el sentido de la acción gubernamental implementada. ${ }^{13}$

El programa "Pinta tu Sueño" convocó a los jóvenes y a la comunidad a distintas actividades, tales como la formación de un comité comunitario, la pinta de bardas y la celebración de diversos talleres de prevención de la violencia y promoción de la cultura de paz. Para la pinta de bardas, convocó principalmente a los jóvenes del lugar, pero sólo acudió un grupo, conocido como "Los CPE", de la calle Río Guaymas, y participaron algunos jóvenes de la secundaria. En total, los participantes pintaron 70 bardas de la colonia.

Cuantitativamente, el programa cumplió con el resultado previsto, pero la realidad fue otra, pues las características de la política gubernamental no lograron desactivar la crítica ni la violencia prevalecientes. En primer lugar, la participación de los jóvenes fue escasa. A la convocatoria que se hizo para la pinta de bardas, sólo respondió el grupo referido, cuyos integrantes no suman más de 10 jóvenes.

En este contexto, cuando los pocos jóvenes que decidieron participar empezaron a pintar, un grupo rival se acercó a pedir latas de pintura y espacios para participar.

\footnotetext{
${ }^{13}$ Esto se pudo observar directamente durante el desarrollo del programa. Además, el consumo de drogas y alcohol es común en las calles.
} 
Evidentemente, los ejecutores del programa no contaron con que esto reavivaría los conflictos y fue motivo de riñas, porque el grupo que entró cuando la actividad había comenzado rayó el trabajo del primer grupo y hubo peleas. Los jóvenes entrevistados narran que dentro y fuera de la secundaria: "se robaron latas y las utilizaron para drogarse". 14

Otra de la acciones del gobierno fue implementar diversos talleres de prevención. En ellos también fue escasa la participación. La mayor parte de los asistentes fueron señoras, madres de familia de las escuelas, adultos mayores y niños de la primaria (que participaron obligados por la Dirección de la escuela); los jóvenes -a quienes estaban dirigidos principalmente los talleres- no participaron.

En los dibujos de algunos de los niños se puede observar un patrón similar al presente en los de los jóvenes: debilitamiento del tejido familiar, pues en las obras hay familias cuyos hijos están solos o se quedan a cargo de sus abuelos. En otras palabras, se reconoce la importancia de la familia para prevenir, de acuerdo con la lógica del taller, pero, al mismo tiempo, se reconoce la imposibilidad objetiva de que la familia se integre “idealmente", pues algunos de los miembros de la familia están en la cárcel, trabajan todo el día o dejaron definitivamente el núcleo familiar, es decir, la política no alcanza a recoger completamente la problemática, pues no va a las raíces del problema. La política asume que la debilidad de la familia es una decisión de las propias familias y no una consecuencia de muchos otros determinantes.

\section{CONCLUSIONES}

Entre los jóvenes de Menchaca II, lo que se reclama principalmente es la desprotección afectiva de la familia. Esta situación tiene un origen múltiple, pues no sólo se debe a la ruptura del vínculo afectivo por razones económicas, sino también por un Estado que se presenta, sobre todo, como agente punitivo. La crítica aparece como falta de respeto, pero también en forma de tristeza.

Hay una crítica a la autoridad, que entre los jóvenes significa falta de consideración hacia su persona, trayectoria e intereses, pero también violencia y estigma. En ese sentido, para ellos, la política es violencia y reeducación, pero nunca respeto. En esta distancia, hemos detectado un primer elemento en la producción del respeto. El distanciamiento del orden hegemónico surge como un primer paso para defenderse de la

\footnotetext{
${ }^{14}$ Esto fue contado por los profesores de la secundaria entrevistados.
} 
violencia. Significa salirse de una red que no da soporte a su existencia e incluso, a veces, resulta peligrosa, por lo tanto, es productora de violencia.

La crítica implica salirse del orden dominante para comenzar a construir una barrera que separe, pero también defienda. En esa medida, el muro es, en primera instancia, una construcción que, por defensiva, parece primordialmente reactiva, pero no lo es. ¿Quién podría decir que la utopía que imaginó Tomás Moro era sólo reactiva y no también creativa? Por eso, en nuestra concepción, la crítica es algo más. Es también una posibilidad política, es decir, una posibilidad para la acción. La crítica es un paso en la producción de respeto; no puede quedarse sólo en reprobación y distanciamiento. Trasciende hacia la acción, y ésta acontece en modos diversos según la interpretación y lógica de los sujetos.

En el rastreo para comprender la producción del respeto, nos hemos topado de lleno con otra de las paradojas del momento actual. El orden o el desorden neoliberal han hecho surgir al sujeto crítico. El abandono del Estado y sus políticas productoras del sujeto han traído a la vida a un sujeto que estuvo dormido en épocas pasadas. Se trata de un sujeto que, en principio, es productor de la crítica; más aún, no sabemos si esto es una esperanza o anuncia la reproducción del estado caótico en el que vivimos. Aún no tenemos claridad sobre los alcances de la crítica, pero los casos de estudio nos aportan algunas pistas en este sentido.

Los jóvenes de Menchaca II representan una manera radical de producir respeto. En este sector, la crítica se orienta a la ruptura del vínculo afectivo en la familia; esto les ha significado abandono y violencia, pero también actitudes que oscilan entre la tristeza y el odio. Ganarse el respeto pasa por la construcción de una comunidad de pares que genere un orden con una doble funcionalidad. Al interior, este orden tiene reglas y prácticas que restituyen el vínculo afectivo roto, a través de una amistad que raya en la hermandad. La solidaridad es la regla y el valor por excelencia y, si es necesario, se está dispuesto a defenderla hasta la muerte. Los miembros del grupo son el objeto/sujeto de la solidaridad que demuestra la creación del nuevo vínculo afectivo. Este colectivo funge como una barrera de protección y seguridad frente a la desprotección del mundo exterior; es un espacio en el que se les acepta y reconoce sin condiciones.

Tan fuerte es el respeto que aporta esta comunidad de pares, que su preservación constituye una necesidad básica. Al interior, el respeto a las reglas es una condición para su preservación, pero la batalla más dura parece acontecer por fuera de sus límites. El afuera, más que un territorio ajeno, representa el hábitat del enemigo, que es todo lo diferente a quienes integran la comunidad: la policía, pero también la banda rival y el 
mundo adulto $^{15}$ que no les muestran respeto y representan la posibilidad de que su comunidad se disuelva; de ahí que haya que combatirlos como a enemigos. El otro es diferente y se le aniquila negándolo, por eso es que la violencia es el recurso por excelencia para proceder contra el otro. No sólo es violencia física, en términos de la aniquilación del otro, sino violencia simbólica en términos de su negación. Así, la violencia es un recurso para la generación de respeto entre los jóvenes de Menchaca II, porque les garantiza la continuidad del reconocimiento que sólo la comunidad construida les proporciona.

Durante los últimos cinco de años, en Menchaca II hubo un importante incremento de la violencia y la delincuencia, y las pandillas tuvieron un crecimiento casi exponencial. Paradójicamente, este reclamo violento de los jóvenes representó un mejoramiento general en la seguridad de toda la comunidad. Al respecto, aunque se han multiplicado los recursos para ellos, los jóvenes consideran las políticas gubernamentales como algo ajeno, vacío y que les sigue faltando al respeto, porque no considera sus necesidades, intereses ni maneras de sentir y expresarse. El encuentro entre los jóvenes y el Estado parece estar signado por la imposibilidad de reconocimiento mutuo y, por ende, de diálogo y acercamiento. Los jóvenes no están dispuestos a negociar el orden, mucho menos, si no se les reconoce.

\section{REFERENCIAS}

ARENDT, H. (2009). ¿Qué es política? Barcelona: Paidós.

AriZA, M. y De OliveirA, O. (coords.) (2004). Imágenes de la familia en el cambio de siglo. México: Universidad Nacional Autónoma de México (UNAM).

Ballesteros de Valderrama, B. P., Contreras, C. E., Vargas, F. J., Palacios, S. R. y BONILLA, L. P. (2002). La pandilla juvenil: breve revisión y análisis funcional de un caso International. Journal of Clinical and Health Psychology, 2(2), pp. 335-350.

Basombrío, C. y Dammert, L. (2013). Seguridad y populismo punitivo en América latina: lecciones corroboradas, constataciones novedosas y temas emergentes. Washington, D. C.: Woodrow Wilson Center Press.

Bauman, Z. (2011). Daños Colaterales. Desigualdades sociales en la era global. México: Fondo de Cultura Económica (FCE).

${ }^{15}$ Reguillo (1997) afirma que hay una construcción mediática en la que se busca señalar a los jóvenes como el nuevo enemigo público; de ahí que no sea casual que los jóvenes sientan la animadversión de no pocos sectores del mundo adulto. 
. (2003). Comunidad. En busca de seguridad en un mundo hostil. Madrid: Siglo XXI Editores.

BECK, U. (1998). La sociedad del riesgo. Hacia una nueva modernidad. Madrid: Paidós.

Berger, P. L. y Luckmann, T. (2003). La construcción social de la realidad. Buenos Aires: Amorrortu.

Buffington, R. (2001). Criminales y ciudadanos en el México moderno. México: Siglo XXI Editores.

Burgois, P. (2010). En busca de respeto. Vendiendo Crack en el Harlem. Buenos Ares: Siglo XXI Editores.

Carrillo, M. A. (2017). El empleo en Querétaro 2009-2016. En Expresiones del trabajo en Querétaro. México: CONCYTEQ, UMEST.

Castel, R. (2013). Políticas del riesgo y sentimiento de inseguridad. En Castel, R., Kessler, G., Merklen, D. y Murard, N., Individuación, Precariedad, Inseguridad ¿Desinstitucionalización del presente? Buenos Aires: Paidós. . (2014). Los riesgos de exclusión social en un contexto de incertidumbre. Revista Internacional de Sociología. Procesos de exclusión social en un contexto de incertidumbre. 72(1), pp. 15-24.

- (2010). El ascenso de las incertidumbres. Trabajo, protecciones, estatuto del individuo. Buenos Aires: FCE.

. (2004) ¿Qué es estar protegido? Buenos Aires: El manantial.

Castillo, H. (2004). Pandillas, jóvenes y violencia. Desacatos, primavera-verano, pp. 105-126. I

Cevallos, F. (2002). Una mirada al nuevo enemigo social: las pandillas juveniles. Iconos. Revista de Ciencias Sociales, 15, pp. 114-122.

Corzo, A. I., Duque, J., Medina, Ll. y Torres, S. (2011). El impacto de las políticas neoliberales en América Latina. Un análisis de la educación en Perú, Colombia y México. Temas de Nuestra América, 50, enero-junio.

Di NAPOli, P. (2016). La juventud como objeto de temor y estigmatización. Sentimientos desde y hacia los jóvenes de los países del Cono Sur. Revista de Ciencias Sociales, 29(38), pp. 123-144.

Dubet, F. (2013). El declive de la institución. Profesiones, sujetos e individuos en la modernidad. Barcelona: Gedisa.

. (2011). Repensar la justicia social. Contra el mito de la igualdad de oportunidades. México: Siglo XXI Editores.

- (2010). Sociología de la experiencia. Madrid: Centro de investigaciones sociológicas/Editorial Complutense.

EsPósito, R. (2012). Inmunidad, comunidad, biopolítica. Las torres de Luca. 1, juliodiciembre.

EsteinOU, Rosario, (2008). La familia nuclear en México: lecturas de su modernidad. Siglos $X V I$ al XX. México: CIESAS/Miguel Ángel Porrúa. 
García-Pelayo, R. (1988). Pequeño Larousse Ilustrado. México: Ediciones Larousse.

Garland, D. (2001). La cultura del castigo. Crimen y orden social en la sociedad contemporánea. Barcelona: Gedisa.

. (1999). Castigo y sociedad moderna. Un estudio de teoría social. México: Siglo XXI Editores.

Gluckman, M. (1958). Análisis de una situación social en zululandia moderna. En Clásicos y Contemporáneos en Antropología. Rhodes-Livingstone Paper 28, pp. 1 27.

Goffman, E. (2012). Estigma. La identidad deteriorada. Buenos Aires: Amorrortu.

Honneth, A. (2011). La sociedad del desprecio. Madrid: Trotta.

HobBes, T. (2016). El Leviatán. Recuperado de: <https: / / freeditorial.com/es/books/leviatan/related-books>.

JANKOWSKI, M. (1991). La banda catalanista. Barcelona: Gedisa.

MARCIAL, R. (1998). La banda rifa. Vida cotidiana de grupos juveniles de esquina en Zamora, Michoacán. México: El colegio de Michoacán (EL COLMICH).

MígueZ, D. y D'Angelo, L. (2006). Relaciones relativas: Desempleo y delito en la provincia de Buenos Aires (1980-2000). Desarrollo Económico. 46(182), pp. 267293.

Moro, T. (2012). Utopía. Madrid: Alianza.

PereA, C. (2007). Con el diablo adentro: pandillas, tiempo paralelo y poder. México: Siglo XXI Editores.

RAmíreZ, A. (2019). De la inseguridad a la seguridad. Tesis doctoral. México: Universidad Autónoma de Querétaro.

y Belmont, E. (2017). Inseguridad y punitivismo populista en Querétaro. Visión criminológica y criminalística, enero-marzo.

Reguillo, M. (2012). Culturas Juveniles: formas políticas de desencanto. Buenos Aires: Siglo XXI Editores.

- (2010). Los jóvenes en México. México: FCE.

Reguillo R. (2008). Inclusión y ciudadanía: perspectivas de la juventud en Iberoamérica. Pensamiento Iberoamericano, 3, pp. 205-225.

- (2003). Ciudadanías Juveniles en América Latina. Última década, 11(19), noviembre.

(1997). Jóvenes y medios: la construcción del enemigo. Chasqui, 60, pp. 16-19.

Saraví, G. (2004). Transiciones vulnerables: los jóvenes en el México contemporáneo. México: CIESAS.

SChmitT, C. (2009). El concepto de lo político: texto de 1932 con un prólogo y tres corolarios. Madrid: Alianza.

Smutt, M. y Miranda, J. (1998). El fenómeno de las pandillas en El Salvador. San Salvador: UNICEF/FLACSO. 
Sunkel, G. (2006). El papel de la familia en la protección social en América Latina. Santiago de Chile: CEPAL/ONU.

VAlenZuela, A. (2009). Violencia y control social del territorio: políticas de seguridad pública en la ciudad de México. Ponencia presentada en el Foro Interdisciplinario "Orígenes de la violencia en México". México: Museo Nacional de Antropología e Historia-Auditorio Jaime Torres Bodet.

Waquant, L. (2009). Punishing the poor. The neoliberal government of social insecurity. Durham, Carolina del Norte: Duke University Press.

WOLF, S. (2017). Mano dura: el populismo ante el crimen y las pandillas. Nexos, febrero. Recuperado de $<$ https://seguridad.nexos.com.mx/?p=49>. 